\title{
Surveillance of Musculoskeletal Symptoms and Anthropometric Variables among Four International Cricket Teams Competed in ACC Premier League Malaysia 2014
}

\author{
Srinivas Mondam ${ }^{1}$, Rahul Shaik², Jalaja Prakash ${ }^{1}$, Jeffrey Low Fook ${ }^{1}$ and Sirisha Nekkanti ${ }^{2}$ \\ ${ }^{1}$ Faculty of Sports Science and Coaching, University Pendidikan Sultan Idris (UPSI), Perak, Malaysia; \\ vasmpt@gmail.com \\ 25IMS College of Physiotherapy, Guntur, India
}

\begin{abstract}
Background and Purpose: Chronic musculoskeletal injuries are more common in cricket players. Acute problems may be due to trauma or injuries during sporting. The musculoskeletal system includes muscles, joints, bones, cartilage, ligaments, fascia, nerves and other associated soft tissues. Whatever the mode of injury, it causes pain, movement restriction, muscle weakness, and ultimately loss of functions. Anthropometric variables of each player in cricket will also influence the occurrence of problems. The current study focused on identifying the most common site involved in musculoskeletal problems and to explore possible variations in anthropometric characteristics. Methodology: This study was conducted in Kuala Lumpur, Malaysia where Asian Cricket Council Premier League 2014 was conducted. Permission to approach the players was taken from the council members and all the players were assured that the information collected from them will be kept confidential and all were explained about the objective study. Modified Nordic musculoskeletal questionnaire was distributed to the players and instructions were given about how to fill the questionnaire. Their anthropometric characteristics, experience and time of training sessions were collected by a blinded assessor. Results: Player's height $(p=0.003)$, weight $(p=0.050)$, experience $(p=0.001)$ and practicing hours per week $(0.002)$ were analyzed. There is a statistically significant difference in these characteristics was observed. Occurrence of acute troubles (within 7 days) of upper back and elbow region were found different in four teams with a P value of 0.007 and 0.022 respectively. Persistence of neck, shoulder and lower back troubles in the last one year has a significant difference between the groups with a $P$ value of $0.014,0.003$ and 0.021 respectively. Conclusion: This study can conclude that the prevalence of musculoskeletal injuries is more in cricket. Especially shoulder, neck, lower limbs and lower back. The incidence of acute problems is more in elbow and upper back regions. This may be acute injuries but not due to chronic over use. The anthropometric variations between groups participated in ACC premier league, Malaysia 2014 was also significantly differing from each other.
\end{abstract}

Keywords: Anthropometric Variations, Cricket Injuries, Musculoskeletal Injuries, Risk Factors for Cricket Injuries

\section{Introduction}

Cricket is the second most popular sport worldwide ${ }^{1,2}$. There are several studies which explain the injuries of soft tissues like muscles, joints, tendons and ligaments. The risk of getting injured is more during fast bowling, fielding, and batting. The involvement of lower limbs $(22.8 \% \text { to } 50.0 \%)^{3-5}$ is more when compared to upper limbs and back. Some studies on young fast bowlers reviled that acute lower limb soft tissues injuries are occurring while participating in matches and practices during the early part of the season ${ }^{6}$. The reasons for acute injuries in young cricket players were explained as the demands on the musculoskeletal system, incorrect technique, poor preparation and training, overuse, and environment. These studies were concentrated on ocular

* Author for correspondence 
injuries, splenic rupture and other acute multi system injuries ${ }^{7,8}$ but not on musculoskeletal problems.

The influence of extrinsic factors will be strengthened when the intrinsic factors are at a disadvantage. So the influences of intrinsic factors in sports need to be studied biomechanically ${ }^{9}$. Various anthropometric characteristics and positioning of body parts in relation to other during sport activity are more considered as intrinsic factors. Predicting the sports performance with anthropometric variables is common and the available evidence for existence of correlation between these two is not strong. The physique plays important role in sports. Proportions of body parts and Morphological constitutions in the human body are genetically determined factors. These cannot be changed under normal circumstances. Even though physical fitness is trainable factor, the influence of physique and body compositions is genetically predisposed. Anthropometric characteristics will be considered as an important factor when dealing with high levels of physical performance ${ }^{10}$. Studies have also shown that champions of different sports require different body proportions with respect to their events ${ }^{11-13}$. We can frame standardized physical characteristics as one of the selecting criterion for different sports, if the influence of physique on each sport performance is clearly studied.

\section{Methodology}

This study was conducted in Kuala Lumpur, Malaysia where Asian Cricket Council Premier League 2014 was conducted. Permission to approach the players was taken from the council members. A total of 5 teams were identified in the competition and only four teams were willing to participate in this study. All the players were assured that the information collected from them will be kept confidential and all were explained about the objective study. Modified Nordic musculoskeletal questionnaire was distributed to the players and instructions were given about how to fill the questionnaire. Their anthropometric characteristics, experience and time of training sessions were collected by a blinded assessor. ANOVA was used to analyze the differences in anthropometric variables and musculoskeletal complaints among four different cricket teams.

\section{Results}

Musculoskeletal problems in all four groups were analyzed and the results were summarized in a pie diagrams. In the last one year Players experienced more problems in shoulder region and back region. Non specific back problems are occupying a larger area in the pie diagram. But when upper back and lower back were analyzed separately both are in same proportion. Problems in ankle region are in the third place (Figure 1).

Most of the players reported that they have prevented from work due to shoulder problems in the last one year. Lower back, upper back and ankle problems are in the next three places which prevented the players from work. Few of the players reported troubles in knee and wrist area. Nobody have prevented from working due to troubles in neck, elbow and hip regions (Figure 2).

The problems experienced in the last seven days (7 days before the data was collected) are analyzed and the results are indicating that the problems which prevented in the last 12 months are responsible to cause troubles in the week before the commencement of actual competition. Shoulder and upper back problems occupied first two places. Lower back is in the third place and ankle is the fourth region in which cricket players experienced problem in last seven days (Figure 3).

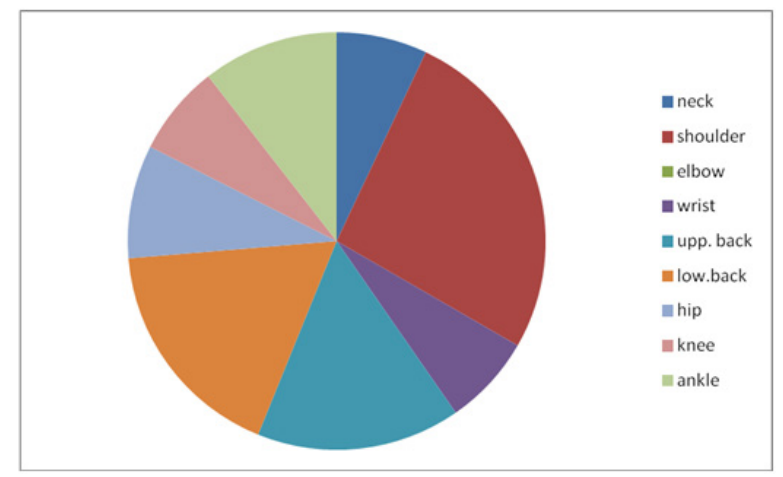

Figure 1. Musculoskeletal problems at various parts of body in the last 12 months.

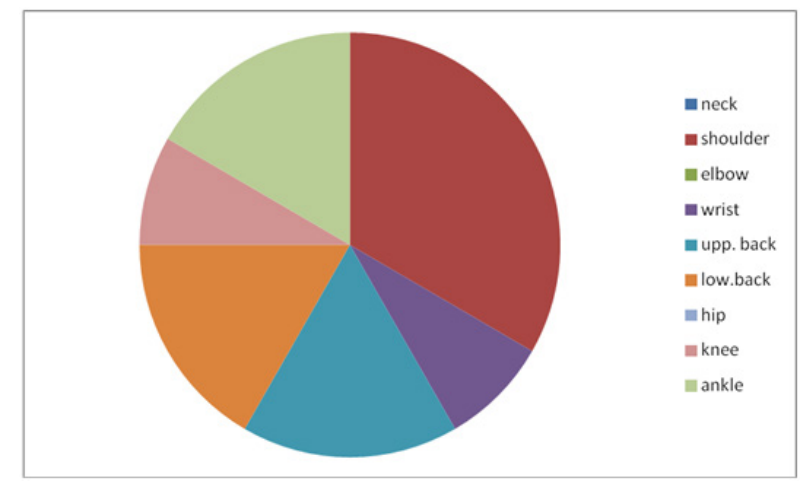

Figure 2. Musculoskeletal problems which preventing from doing work in the last 12 month. 


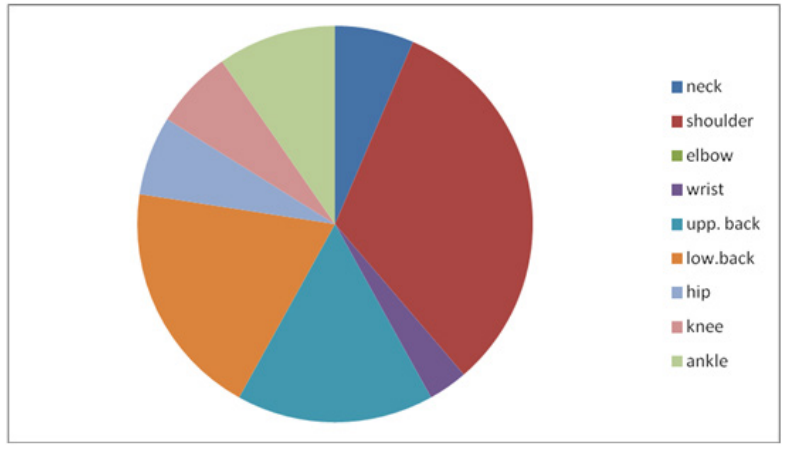

Figure 3. Musculoskeletal problems which the players experienced in last 7 days.

Various anthropometric variables, practicing hours and experience were statistically analyzed by using the software S.P.S.S - version 20. One way ANOVA was used to find out the between group differences in anthropometric characteristics and experience of players in four groups. Player's height, weight, experience and practicing hours per week were analyzed. There is a statistically significant difference in these characteristics was observed (Table 1).

The occurrence of various musculoskeletal troubles in each team was analyzed by using descriptive statistics and the difference in the occurrence of musculoskeletal troubles between four groups was measured by using Chi-Square Test. The prevalence of hip, knee, ankle and wrist troubles is same in all the groups. Differences in the prevalence of wrist problems in the last 7 days were not able to compute due to the constant absent of this problem in all players.
Persistence of neck, shoulder and lower back troubles in the last one year has a significant difference between the groups with a $\mathrm{P}$ value of $0.014,0.003$ and 0.021 respectively. The percentage of players with neck pain is more in Hong Kong (58.3\%) cricket team, shoulder pain is more in Nepal cricket team (71.4\%) and Malaysian cricket team is facing more trouble in lower back (20\%), no team is prevented by musculoskeletal problems except Malaysian team with $20 \%$ of players facing upper back troubles and there is a difference between four teams $(\mathrm{P}=$ 0.047) in upper back troubles which prevented from work in the last one year.

Occurrence of acute troubles (within 7 days) of upper back and elbow region were found different in four teams with a $\mathrm{P}$ value of 0.007 and 0.022 respectively. $30 \%$ of Malaysian team is reported upper back pain within last 7 days. $25 \%$ of Hon Kong team is also having acute problems in elbow region. In general omen cricket team is not reported considerable musculoskeletal troubles.

\section{Discussion}

The results of this study clearly expressing the variations in anthropometric characteristics among four cricket teams and their musculoskeletal problems. All the teams are suffering from shoulder problems in common. Upper back and lower back troubles are also commonly reported in cricket players. There are statistically significant differences between all groups in respect to their anthropometric characteristics. Hon Kong, Nepal

Table 1. Variation in anthropometric variables, experience and practicing hours

\begin{tabular}{|c|c|c|c|c|c|c|}
\hline \multicolumn{7}{|c|}{ ANOVA } \\
\hline & & Sum of Squares & df & Mean Square & $\mathrm{F}$ & Sig. \\
\hline \multirow[t]{3}{*}{ ht } & Between Groups & 1.863 & 3 & .621 & 5.372 & .003 \\
\hline & Within Groups & 5.088 & 44 & .116 & & \\
\hline & Total & 6.951 & 47 & & & \\
\hline \multirow[t]{3}{*}{ wt } & Between Groups & 816.289 & 3 & 272.096 & 2.812 & .050 \\
\hline & Within Groups & 4257.190 & 44 & 96.754 & & \\
\hline & Total & 5073.479 & 47 & & & \\
\hline \multirow[t]{3}{*}{$\exp$} & Between Groups & 141.844 & 3 & 47.281 & 6.554 & .001 \\
\hline & Within Groups & 317.426 & 44 & 7.214 & & \\
\hline & Total & 459.270 & 47 & & & \\
\hline \multirow[t]{3}{*}{ hrswk } & Between Groups & 1367.400 & 3 & 455.800 & 5.846 & .002 \\
\hline & Within Groups & 3430.600 & 44 & 77.968 & & \\
\hline & Total & 4798.000 & 47 & & & \\
\hline
\end{tabular}


and Malaysia teams are facing problems frequently in different body parts. Oman cricket team is not reported any considerable troubles in any of the body parts.

Anthropometric variations will also play a considerable role in the sports performance. The anthropometric profiles included the measurement of height, weight, skin folds, and segment lengths, breadths, and girths. The relationship between physics and biology may influence the sports performance in relation to the height -based factors in sports. Both below average and above average heights are advantageous in different kinds of sports. Faster reaction times, acceleration, greater endurance, faster rotational capability, agility, greater balance and lower centre of gravity, less heat exhaustion are the advantages of below average height. Greater absolute strength, maximum work capacity, greater power, lower resting metabolic rate and speed are the advantages of above average height. ${ }^{14}$

In cricket, some of the great batsmen are below average height. This may be because a smaller body makes for an advantage in footwork and balance. Similarly, the most graceful wicket-keepers have tended to be average height or below. On the other hand, many of the most successful fast bowlers have been well above average height. Height is not generally seen as an important attribute in rugby league football, often with extreme height being a hindrance rather than useful ${ }^{15}$. Analysis of differences between experienced players and starters in cricket revealed that talent identification is based on height, running speed, and agility ${ }^{16}$. Max Stuelcken, David Pyne \& Peter Sinclair studied the Anthropometric characteristics of elite cricket fast bowlers where male players showed significant association of heights with performance. The female bowlers had a higher sum of skin fold thickness, were more endomorphic and less mesomorphic than the male bowlers ${ }^{17}$. There are studies which confirm the relationship between variations in upper limb bones orientation, body mass, strength of upper body and bowling speed variations in cricketers ${ }^{18,19}$.

In a study, conducted by $\mathrm{M} H$ Noorbhai, $80 \%$ of cricket players experienced musculoskeletal pain. The prevalence of problems is more in lower and upper extremities. The lower back occupied third place. Direct trauma is the important predisposing factor for musculoskeletal problems in cricketers, over use is in the next place. The prevalence of cricket-related musculoskeletal pain specific to the various anatomical sites were mostly knee (30\%) and lower back (29\%), followed by shoulder (17\%), ankle (13\%) and thigh (11\%). ${ }^{20}$
In any sport activity Maturation was a significant covariate in anthropometric measures but not in physical performance. Experience and practice are the key factors for improving performance. Few authors were not able to draw a possible relationship between anthropometric variables and sports performance in cricket ${ }^{21}$. Greater the practicing hours greater the skill achieved. Too much practice may lead to overuse injuries, so work load can be considered as a risk factor for sports related injuries ${ }^{22-25}$. It is accepted fact that there are several risk factors for sports injuries. But the thing is to identify the possible relationship between these risk factors and injuries. It is not fare to discuss the sports injuries in relation to intrinsic factors but extrinsic factors should also be considered. Orchard J W et.al; concluded that meaningful comparison of injury surveillance data from different countries and time periods, would assist in the possible identification of risk factors for injury in cricket. ${ }^{26}$

The results of this study can give a picture of musculoskeletal injuries in cricket players and their anthropometric variations. The major limitation of this study is its failure to draw a relationship between these anthropometric variables and prevalence of sports injuries. To achieve this objective the study should consider possible risk factors in cricket, both intrinsic and extrinsic. It will be difficult to study each risk factor in isolation because the sports injuries are the result of cumulative effect of various factors. Future work on physique and sports performance can help us to form selecting guidelines for different sports depending on their physical characteristics.

\section{Conclusion}

This study can conclude that the prevalence of musculoskeletal injuries is more in cricket. Especially shoulder, neck, lower limbs and lower back. The incidence of acute problems is more in elbow and upper back regions. This may be acute injuries but not due to chronic over use. The anthropometric variations between groups participated in ACC premier league, Malaysia 2014 was also significantly differing from each other.

\section{References}

1. Wood R. World's Most Popular Sports by Fans. Topend Sports. 2008. Retrieved 2015-06-23. 
2. Doley A. Most Popular Team Sports: Soccer and cricket, basket ball \& baseball??? Bleacher Report. 2009 May 7. Retrieved 2015-06-23.

3. Temple R. Cricket injuries: fast pitches change the gentleman's sport. Physician and Sports Medicine 1982; 10:18692

4. Stretch RA. Incidence and nature of epidemiological injuries to elite South African cricket players. S Afr Med J. 2001; 91:336-9.

5. Stretch RA. Injuries to South African cricketers playing at first-class level. Journal of the South African Sports Medicine Association. 1989; 4:3-20.

6. Stretch RA. Cricket injuries: A longitudinal study of the nature of injuries to South African cricketers. Br J Sports Med. 2003; 37:250-3. Doi:10.1136/bjsm.37.3.250.

7. Du Toit DF, Rademan F. Splenic rupture caused by a cricket ball. S Afr Med J. 1987; 71:796

8. Jones NP, Tullo AB. Severe eye injuries in cricket. Br J Sports Med. 1986; 20:178-9.

9. Dennis RJ, Finch CF, McIntosh AS, Elliott BC. Use of field-based tests to identify risk factors for injury to fast bowlers in cricket. Br J Sports Med. 2008; 42:477-82.

10. Luhtra CFA, Shaw D. Anthropometry of University Female Athletes. In: Origin of Kinanthropometry. 1990.

11. Sidhu LS, Singh J, Singh SP. Physique and body composition of different categories of Runners. 1990; 95-102.

12. Sodhi HS et al. NWGK Publications Patiala. In: Sharma SS editor. Anthropological study of athletes in Sports College and Sports College and sports hostels in Uttar Pradesh. Ph. D. Thesis, Lucknow University, Lucknow. 1982.

13. Rajendran K. Relationship of Anthropometric Measurements to Performance in Cricket Star Phy Edn. 2013 Aug; $1(9)$.

14. Samaras T. Human body size and the laws of scaling. New York: Nova Science. 2007; 33-61. ISBN 1-60021-408-8. Retrieved 2012-11-18.

15. Gabbett T, Kelly J, Pezet T. Relationship between physical fitness and playing ability in rugby league players. Journal of Strength and Conditioning Research. 2007 Nov. 21(4):1126-33. Doi: 10.1519/R-20936.1. PMID 18076242.
16. Mohamed H, Vaeyens R, Matthys S, Multael M, Lefevre J, Lenoir M, Philippaerts R. Anthropometric and performance measures for the development of a talent detection and identification model in youth handball. Journal of Sports Sciences. 2009; 27(3):257-66. Doi: 10.1080/02640410802482417.

17. Stuelcken M, Pyne D, Sinclair P. Anthropometric characteristics of elite cricket fast bowlers. Journal of Sports Sciences. 2007; 25(14):1587-97. Doi: 10.1080/02640410701275185.

18. Glazier PS, Paradisis GP, Cooper S-M. Anthropometric and kinematic influences on release speed in men's fast-medium bowling. Journal of Sports Sciences. 2000; 18(12):1013-21. Doi: 10.1080/026404100446810.

19. Pyne David B, Duthie Grant M, Saunders Philo U, Petersen Carl A, Portus Marc R. Anthropometric and strength correlates of fast bowling speed in junior and senior cricketers. Journal of Strength and Conditioning Research. 2006 Aug; 20(3).

20. Noorbhai MH, Essack FM, Thwala SN, Ellapen TJ, van Heerden JH. Prevalence of cricket-related musculoskeletal pain among adolescent cricketers in Kwa Zulu-Natal. SAJSM. 2012; 24(1).

21. Hussain I, Arshad M, Bari AK, Mohammad A, Ahmad A. Accuracy - velocity relationship and physical characteristics in cricket ball throwing. International Journal of Sports Science and Engineering. 2011; 05(1):043-8.

22. Saw R, Dennis RJ, Bentley D, Farhart P. Throwing workload and injury risk in elite cricketers. Br J Sports Med. 2011; 45(10):805-8.

23. Dennis R, Farhart P, Goumas C, Orchard J. Bowling workload and the risk of injury in elite cricket fast bowlers. J Sci Med Sport. 2003; 6(3):359-67.

24. Peterson L, Renstrom P. Sports Injuries, Gillingham, Kent, UK. 2001.

25. Finch CF, Elliott BC, McGrath AC. Measures to prevent cricket injuries: An overview. Sports Medicine. 1999; 24(4):263.

26. Orchard JW, Newman D, Stretch R, Frost W, Mansingh A, Leipus A. Methods for injury surveillance in international cricket. Br J Sports Med. 2005; 39(4):e22. 